\title{
Oxidation Versus Carboxamidomethylation of S-S Bond in Ranid Frog Peptides: Pro and Contra for de Novo MALDI-MS Sequencing
}

\author{
Tatiana Y. Samgina, ${ }^{a}$ Konstantin A. Artemenko, ${ }^{a}$ Vladimir A. Gorshkov, ${ }^{a}$ \\ Nikita B. Poljakov, ${ }^{b}$ and Albert T. Lebedev ${ }^{\mathrm{a}}$ \\ ${ }^{a}$ Chemistry Department, Moscow State University, Moscow, Russia \\ ${ }^{\mathrm{b}}$ Institute of Bioorganic Chemistry, Moscow, Russia
}

Five natural peptides isolated from ranid skin secretions of European frog species of Rana ridibunda and Rana arvalis (molecular masses 3516, 2674, 2636, 1874, and $1810 \mathrm{Da}$ ) were studied by MALDI-TOF/TOF to compare two procedures of disulfide bond cleavage: (1) performic oxidation and (2) reduction/carboxamidomethylation. The processes are relevant for the elucidation of the amino acid sequence inside the seven-member cystine ring at the C-terminus. The results clearly demonstrated that oxidation of the disulfide bond led to notably higher abundances of $\mathrm{b}$ - and $\mathrm{y}$-ions, corresponding to the C-terminal peptide bonds, than reduction/carboxamidomethylation. This conclusion is true for all five peptides studied. Besides that, the oxidation procedure is simpler than carboxamidomethylation, as it is a one-step process with no purification required. The oxidation is more reproducible. The results were similar each time the peptide was subjected to the process. It was successfully applied to all five peptides while reduction/carboxamidomethylation failed in the case of brevinin-1Ra, despite all variations of reaction conditions. (J Am Soc Mass Spectrom 2008, 19, 479-487) (C) 2008 American Society for Mass Spectrometry

A skin secretion produced by granular skin glands of anurans in response to a variety of stimuli contains biologically active peptides [1-4]. Our interest was focused on the Rana genus containing a notable array of common frogs spread around the territory of Eurasia and America. A major part of ranid peptides has a disulfide cycle at the C-terminus $[1,5]$. This peculiarity, called "Rana box" [6], complicates sequencing of these peptides. The amino acid sequence inside the cycle is practically unattainable by means of mass spectrometry without preliminary chemical derivatization. There is only one communication on direct sequence identification inside the C-terminus disulfide cycle using ESI MS/MS in the negative ion mode. It deals with some bioactive peptides isolated from genus Crinia (Australia) and with brevinin-1E $R$. ridibunda, (Russia) [7]. In this case, a combination of the positive and negative mass spectra has produced complete sequences for all the investigated peptides. Unfortunately not all peptides give reasonable negative ion spectra.

Mass spectrometric sequencing of disulfide containing peptides requires preliminary modification of the S-S bond. There are two general methods to cleave this bond: (1) reduction followed by the alkylation of cys-

Address reprint requests to Dr. A. T. Lebedev, Chemistry Department, Moscow State University, Leninskie Gory, 1/3, GSP-2, Moscow 119992, Russia. E-mail: lebedev@org.chem.msu.ru teines [8-10]; (2) oxidation with performic acid [11]. The first procedure is traditionally used to break S-S bonds in proteins with associated polypeptide chains before their enzymatic digestion. We applied it for the skin peptides of the Rana genus with an internal disulfide cycle $[12,13]$. Reduction of the S-S bond followed by carboxamidomethylation allows reliable sequencing at the C-terminus. LTQ FTICR mass spectrometric results completely match those obtained by Edman degradation.

Performic oxidation is a well-known method for the cleavage of S-S bonds [14, 15]. It transforms thiol groups of cysteines into sulfonic acids. Besides that, several by-processes may take place, e.g., oxidation of methionine, tyrosine, and tryptophan [11, 16, 17]. Oxidation also results in a sharp increase of the MALDI signals. For example, oxidation of bovine serum albumin (BSA) before its enzymatic digestion [16, 17] significantly enhances the sequence coverage in comparison with traditional reduction/alkylation.

The use of sulfonic acid derivatives for peptide sequencing by MALDI-MS is thoroughly discussed in the recent review [18]. It is shown that introduction of sulfonic groups to the $\mathrm{N}$-terminus of tryptic peptides considerably facilitates the primary structure elucidation. The latter feature makes this approach convenient for the protein identification using database searches.

We used the peroxidation procedure for peptides containing the C-terminal loop formed by a single chain. The previously described examples dealt with 
separate chains connected by S-S link exclusively. The idea involved formation of two strong acidic moieties at the C-terminus of the peptides. Since MALDI is characterized mainly by single charge molecular ions, two additional mobile protons of the formed sulfonic acid groups could change the fragmentation pattern. Thus, the aim of the present study involved comparison of the advantages and shortcomings of performic oxidation versus reduction/carboxamidomethylation for MALDI TOF/TOF de novo sequencing of the peptides containing "Rana box". Five natural skin peptides secreted by Rana ridibunda and Rana arvalis species were used for this purpose.

\section{Experimental}

All the solvents were purchased from Panreac (Barcelona, Spain). Trifluoroacetic acid as well as dithiothreitol and ammonium hydrogen carbonate were purchased from Acros (Moscow, Russia). All chemicals were used without additional purification.

\section{Preparation of Skin Secretions}

Both male and female Rana ridibunda as well as Rana arvalis species were caught in Moscow region. Adult animals were maintained in captivity at the Biology Department of the Moscow State University under conditions close to natural ones. Secretion from the skin glands was provoked by mild electrical stimulation [19] for $40 \mathrm{~s}$ using laboratory electrostimulator ESL-1 equipped with platinum electrodes. The duration of impulse was $3 \mathrm{~ms}$ with amplitude of $10 \mathrm{~V}$ at $50 \mathrm{~Hz}$. The skin secretions were washed from the animals with MilliQ (Millipore, Billerica, MA) water while an equal volume of methanol was immediately added to the aqueous solution. The mixtures were centrifuged and filtered through the PTF membrane filter $(0.45 \mu \mathrm{m})$. The solutions obtained were concentrated using rotary evaporator to a volume of $1 \mathrm{~mL}$ and lyophilized.

\section{HPLC Separation of Crude Secretion}

One milligram of lyophilized skin secretion was dissolved in $1 \mathrm{~mL}$ of distilled water. Peptide separation was performed with an HPLC system (Thermo Fisher Scientific Inc., San Jose, CA) by injecting $50 \mu \mathrm{l}$ of the crude extract into a reverse-phase chromatographic analytical column BiochemMack (Moscow, Russia) $\mathrm{C}_{18}$ $(5 \mu, 110 \AA, 4 \times 150 \mathrm{~mm})$ equilibrated with $10 \%$ acetonitrile/aqueous $0.1 \%$ trifluoroacetic acid. The peptides were purified using a linear gradient from $10 \%$ to $70 \%$ (60 min) acetonitrile containing $0.1 \%$ trifluoroacetic acid. The flow rate was $0.8 \mathrm{~mL} / \mathrm{min}$.

\section{Disulfide Bond Reduction and Alkylation}

HPLC purified and lyophilized peptide fractions were redispersed in ammonium buffer $\left(100 \mathrm{mM} \mathrm{NH} \mathrm{HCO}_{3}\right.$, $\mathrm{pH}$ 8.0) with dithiothreitol at the concentration of $4 \mathrm{mM}$ while nitrogen was flushed to provide an inert atmosphere throughout the reaction [20]. The reaction solution was incubated for $1 \mathrm{~h}$ at $37^{\circ} \mathrm{C}$. Then $10 \mathrm{mM}$ iodoacetamide was added and the mixture was incubated for $1 \mathrm{~h}$ at $37^{\circ} \mathrm{C}$ in the dark.

\section{Performic Oxidation}

Performic oxidation of the peptides was performed as described previously [21]. The peptides were dissolved in formic acid and incubated for $2.5 \mathrm{~h}$ with triple volume excess of performic acid at $0{ }^{\circ} \mathrm{C}$. For preparing of the latter, one part of hydrogen peroxide was mixed with 19 parts of formic acid (room temperature, $2 \mathrm{~h}$ ). Finally, s five volume excess of Milli-Q water was added, and the resulting solution was lyophilized.

\section{Amino Acid Sequencing}

The purity check of each separated fraction and further MS/MS experiments were carried out with MALDITOF/TOF instrument (Ultraflex TOF/TOF, Bruker Daltonik, Bremen, Germany). MS/MS experiments were performed in the reflectron mode using mass range of $\mathrm{m} / \mathrm{z} 50$ to 3000. Instrument was calibrated using standard peptide mixture (PepMix-2, Bruker Daltonik, Bremen, Germany) before the measurements. Laser power and multiplier voltage were modified during MS/MS experiments to maximize intensities and parent ion resolution. Applying the abovementioned parameters, an optimized sum of 600 individual laser shots was collected for each sample and the resulting spectra were analyzed and compared.

\section{Results and Discussion}

Both procedures of modification of S-S bond are schematically presented in Scheme $\mathbf{1}$.

Oxidation presents a number of advantages over reduction/carboxamidomethylation: (1) as Scheme 1 demonstrates, it is a single stage process; (2) subsequent purification of the sample is not required as lyophilization eliminates all the oxidation reagents; (3) the process is universal and reproducible as oxidation is independent of the peptide nature. Its drawback involves possible oxidation of Met, Tyr, Thr, together with Cys. The latter processes result in the changes of the mass differences between the ions of $b$ - and $y$-series [17].

Table 1 represents five disulfide containing peptides isolated from the skin secretions of $R$. Arvalis and $R$. ridibunda. Their structures were elucidated earlier by mass spectrometry and confirmed by Edman degradation $[12,13,22,23]$.

\section{Brevinin-1Ava and Brevinin-1Ra}

Mass spectrum of a disulfide-containing peptide brevinin1AVa (MW $1810 \mathrm{Da}$ ) isolated from the skin secretion of $R$. arvalis is shown in Figure 1a. The spectrum lacks all 


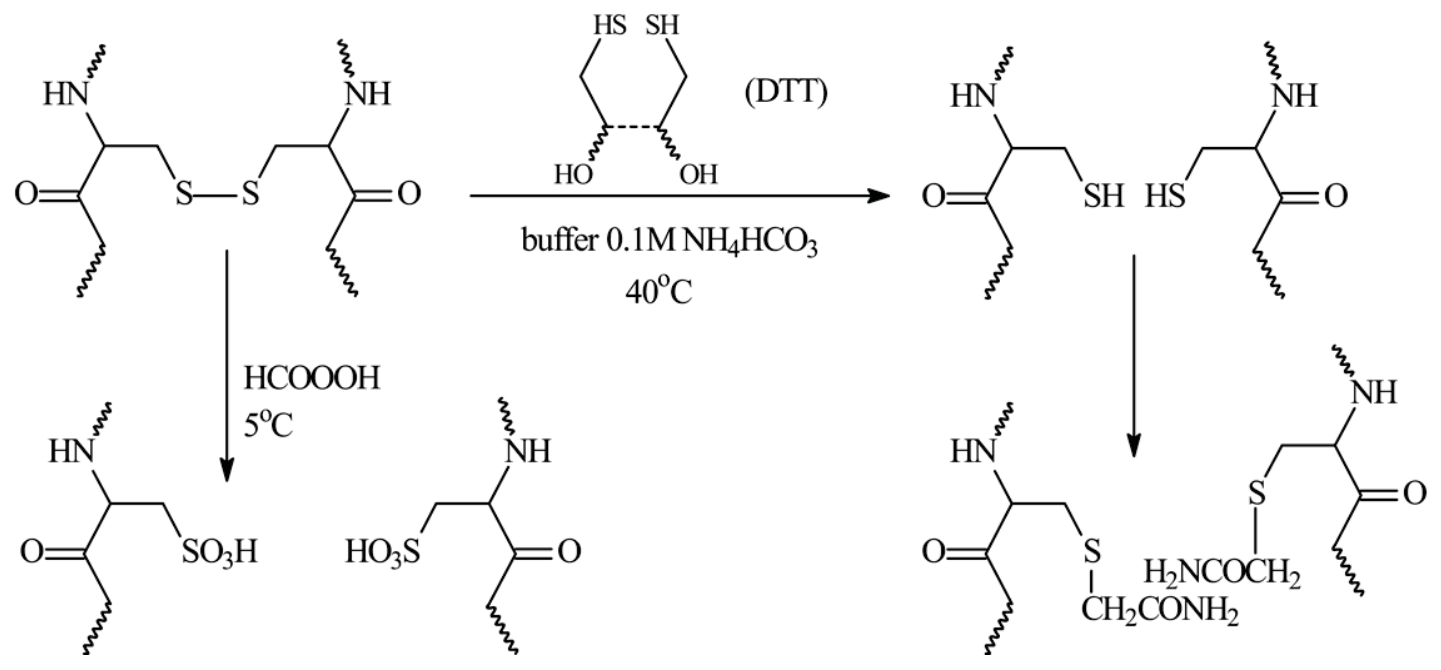

Scheme 1

the peaks revealing fragmentation from the C-terminus. This feature is characteristic for the peptides with disulfide cycle. Figure $1 \mathrm{~b}$ represents MALDI MS/MS spectrum of the same peptide after reduction of S-S bond with dithiothreitol and alkylation of Cys residues with iodoacetamide. The mass spectrum of oxidized sample is shown in Figure 1c.

To obtain a reliable comparison of spectral quality, a parameter of signal-to-noise ratio $(\mathrm{S} / \mathrm{N})$ for all the peaks of $b$ - and y-ions may be used. Figure 2 represents a histogram where $b$ - and $y$-ions are compared for the MALDI spectra of carboxamidomethylated and oxidized brevinin-1AVa at the same scale.

These histograms clearly demonstrate the general notable increase of the $\mathrm{S} / \mathrm{N}$ ratio for the oxidized sample versus the carboxamidomethylated. $\mathrm{S} / \mathrm{N}$ ratios of $\mathrm{b}$ - and $\mathrm{y}$-ions peaks corresponding to the cleavages inside the former disulfide cycle are also notably higher. This feature makes de novo sequencing of the oxidized peptides more reliable.

Oxidation transforms the thiol groups of cysteines into sulfonic acid moieties, which are much stronger than aspartic or glutamic acids [24]. The acidic hydrogen atoms may play a role of mobile protons. Thus, MALDI experiments may bring a quasi triple charge state of the molecular ions (rather than the usual single charge). Proton affinity decreases in the order Arg $\gg$ Lys His [25]. Since the C-terminus of brevinin-1AVa contains two lysines, the protons of neighboring sulfonic acids will presumably be localized at the amino groups of the side chains. As lysine, in contrast to arginine, is incapable of holding the protons in place, these two protons may be partially available for the protonation of other amino acid residues. Therefore, all three mobile protons may trigger fragmentation of the molecular ion of brevinin-1AVa. This possibility results in a sharp increase of the spectral peaks intensities and in lengthening of $b$ - and $y$-series (Figure $2 a$ ). $S / N$ values of $y$-series are higher than those of $b$-series due to two terminal lysines providing the sites of preferential protonation in this peptide. These particular positions of lysines make y-series dominate over b-series (Figure $2 \mathrm{~b}$ ). In the case of carboxamidomethylation, additional protons are absent and fragmentation may be initiated only by one mobile proton. As a result, the abundances of $b$ - and $y$-ions are low and quite similar (Figure $2 b$ ).

The mass spectrum of oxidized brevinin-1Ra and corresponding histogram is shown in Figure 3. The C-terminus of this peptide contains two arginines. Due to its high proton affinity, arginine captures a proton that initiates a selective cleavage of the peptide chain $[26,27]$. Since two acidic sulfonic moieties at

Table 1. Peptides from the skin secretions of $R$. ridibunda and $R$. arvalis

\begin{tabular}{cclll}
\hline \multicolumn{2}{c}{ MW $(\mathrm{MH}+)$} & & \\
$\begin{array}{c}\text { Theoretical } \\
\text { monoisotopic }\end{array}$ & $\begin{array}{c}\text { Used for } \\
\text { MS/MS* }\end{array}$ & & \multicolumn{1}{c}{ Species } & \multicolumn{1}{c}{ Name } \\
\hline \hline 1810.96 & 1810.95 & FLPLLAASFACTVTKKC-OH & R. arvalis & \multicolumn{1}{c}{ Brevinin-1AVa } \\
1874.10 & 1874.17 & FVPLLVSLVCVVTKKC-OH & R. arvalis & Brevinin-1AVb \\
3517.92 & 3519.03 & GILLDKLKNFAKTAGKGVLOSLLNTAS-CKLSGOC-OH & R. ridibunda & Brevinin-2Ec \\
2675.53 & 2676.75 & FLPLLAGLAANFLPKIFCKITRKC-OH & R. ridibunda & Brevinin-1E \\
2637.25 & 2638.18 & VIPFVASVAAEMMOHVYCAASRRC-OH & R. ridibunda & Brevinin-1Ra \\
\hline
\end{tabular}

*The most abundant ion in the molecular ion isotopic cluster was used in the MS/MS experiments. 

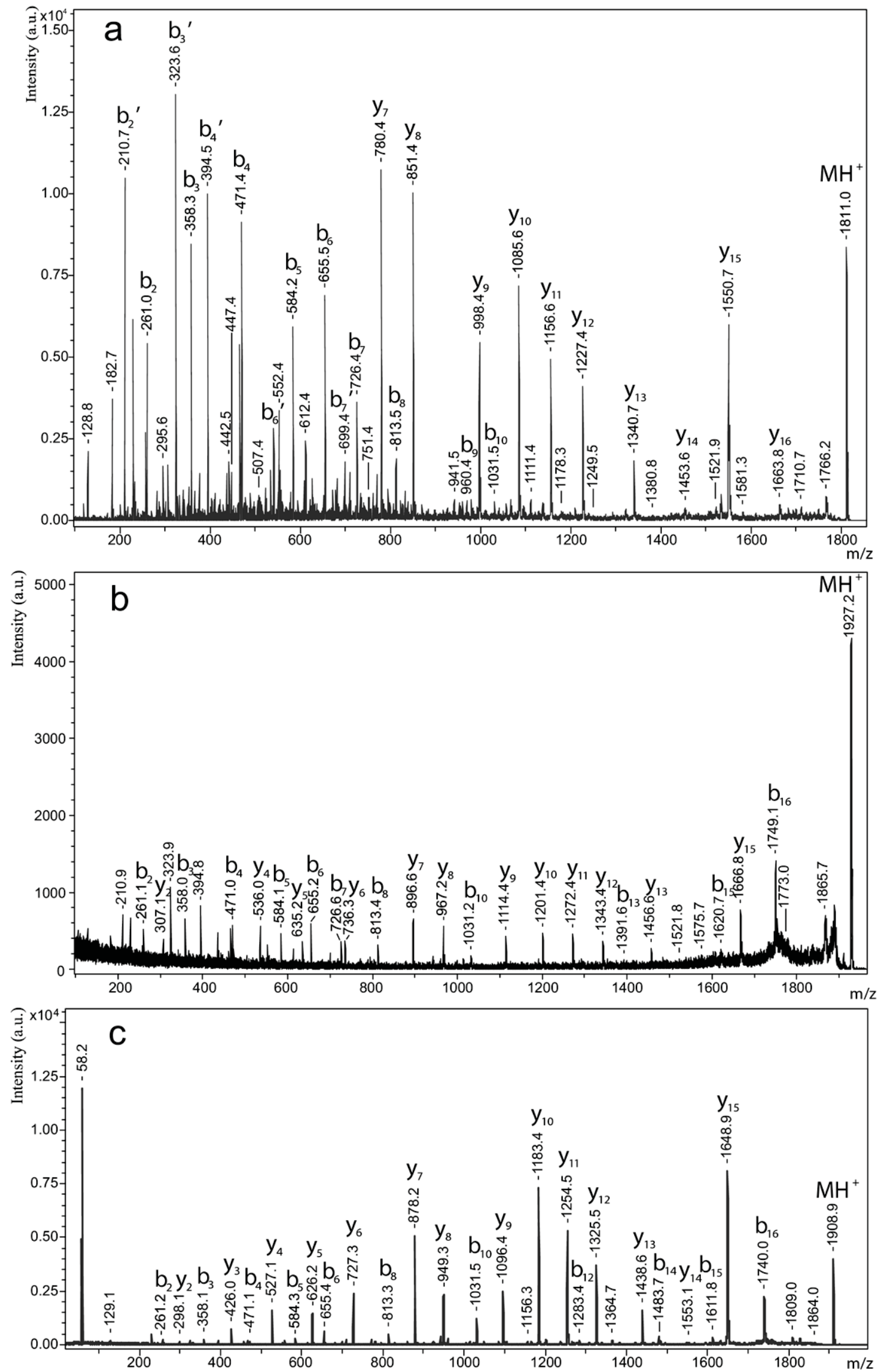

Figure 1. MALDI-TOF/TOF spectra of intact brevinin-1AVa (a), brevinin-1AVa after reduction/ carboxamidomethylation (b), and after oxidation (c) of disulfide bond. 




Figure 2. Signal-to-noise ratio for fragment ions peaks. Oxidized brevinin-1AVa (a), carboxamidomethylated brevinin-1AVa (b).

the C-terminus of the oxidized peptide adjoin two arginines, two zwitterions may be proposed as the most preferable structure [28]. Therefore, only one mobile proton may participate in a protonation of other suitable sites of brevinin-1Ra. In the absence of other basic amino acids, random intensities of all the other peaks of y-ions could be the case. However, the presence of histidine makes the corresponding site more preferable for the proton localization [28]. As a result, the mass spectrum of brevinin-1Ra contains four extremely intensive peaks of $\mathrm{y}_{3}-\mathrm{y}_{6}$ ions (previously blocked "Rana box" region) and an intensive peak of $\mathrm{y}_{10}$ ion, which corresponds to the cleavage at the N-terminus of histidine. The integral intensity of $y$-series is significantly higher than that of b-series due to the presence of two basic arginines at the C-terminus of brevinin-1Ra. The characteristic neutral loss of $80 \mathrm{Da}$ $\left(\mathrm{MeSO}_{2} \mathrm{H}\right)$ is also observed [29]. This loss indicates the presence of oxidized methionine in the peptide sequence. The presence of two oxidized methionines is confirmed by MS/MS data: the mass difference between $b_{13}$ and $b_{12}$ ions as well as between $y_{12}$ and $y_{11}$ and between $y_{13}$ and $y_{12}$ equals $163 \mathrm{Da}\left(\operatorname{Met}\left(\mathrm{O}_{2}\right)\right)$.

It should also be emphasized that reduction/alkylation approach was completely unsuccessful in the case of brevinin-1Ra. The standard procedure described above as well as variation of temperature $\left(36^{\circ} \mathrm{C}, 80^{\circ} \mathrm{C}\right)$ and reaction time (15 $\mathrm{min}, 60 \mathrm{~min}$ ) did not bring any positive result. The reaction mixture of brevinin-1Ra subjected to carboxamidomethylation was analyzed by MALDI-TOF and no other peak except the intact peptide was reveled. Thus, carboxamidomethylation has not been achieved while oxidation was successful and easy.

\section{Brevinin-2Ec and Brevinin- $1 A V b$}

These peptides have basic lysines at the $\mathrm{C}$-terminus and at the acyclic backbone. Figure 4 demonstrates the MS/MS data as a histogram of $\mathrm{S} / \mathrm{N}$ ratios for $\mathrm{b}$ - and $\mathrm{y}$-ions.

Ion $\mathrm{y}_{29}$ peak is the most intensive in $\mathrm{y}$-series of the carboxamidomethylated brevinin-2Ec. It forms as a result of peptide bond cleavage between Asp5 and Lys6. In the case of a single mobile proton (carboxamidomethylation procedure) only aspartic acid may render an additional proton to the amino group of the neighboring lysine $[28,30]$. The intensity of the $y_{29}$ peak decreases twice with the appearance of two additional mobile protons due to oxidation of $\mathrm{S}-\mathrm{S}$ bond of brevinine-2Ec into sulfonic acids (Figure $4 a, b$ ).

It should be emphasized that random distribution of basic lysines along the backbone results in higher sequence coverage for both $\mathrm{S}-\mathrm{S}$ bond modifications. This structural phenomenon makes possible the sequencing of long peptides.

In the case of brevinin- $1 \mathrm{AVb}$, again neither $\mathrm{S} / \mathrm{N}$ enhancement nor b- or y-series domination is observed for the two sample preparation procedures. However, the sum of $\mathrm{S} / \mathrm{N}$ ratios for oxidized peptide is higher for both $b$ - and y-series corresponding to the cleavages inside former disulfide bridge. This means oxidation is preferable for de novo sequencing inside the disulfide cycle.

\section{Brevinin-1E}

The histogram of $\mathrm{S} / \mathrm{N}$ ratios for the ions of $\mathrm{b}$ - and $\mathrm{y}$-series of oxidized brevinin-1E is shown in Figure 5. 

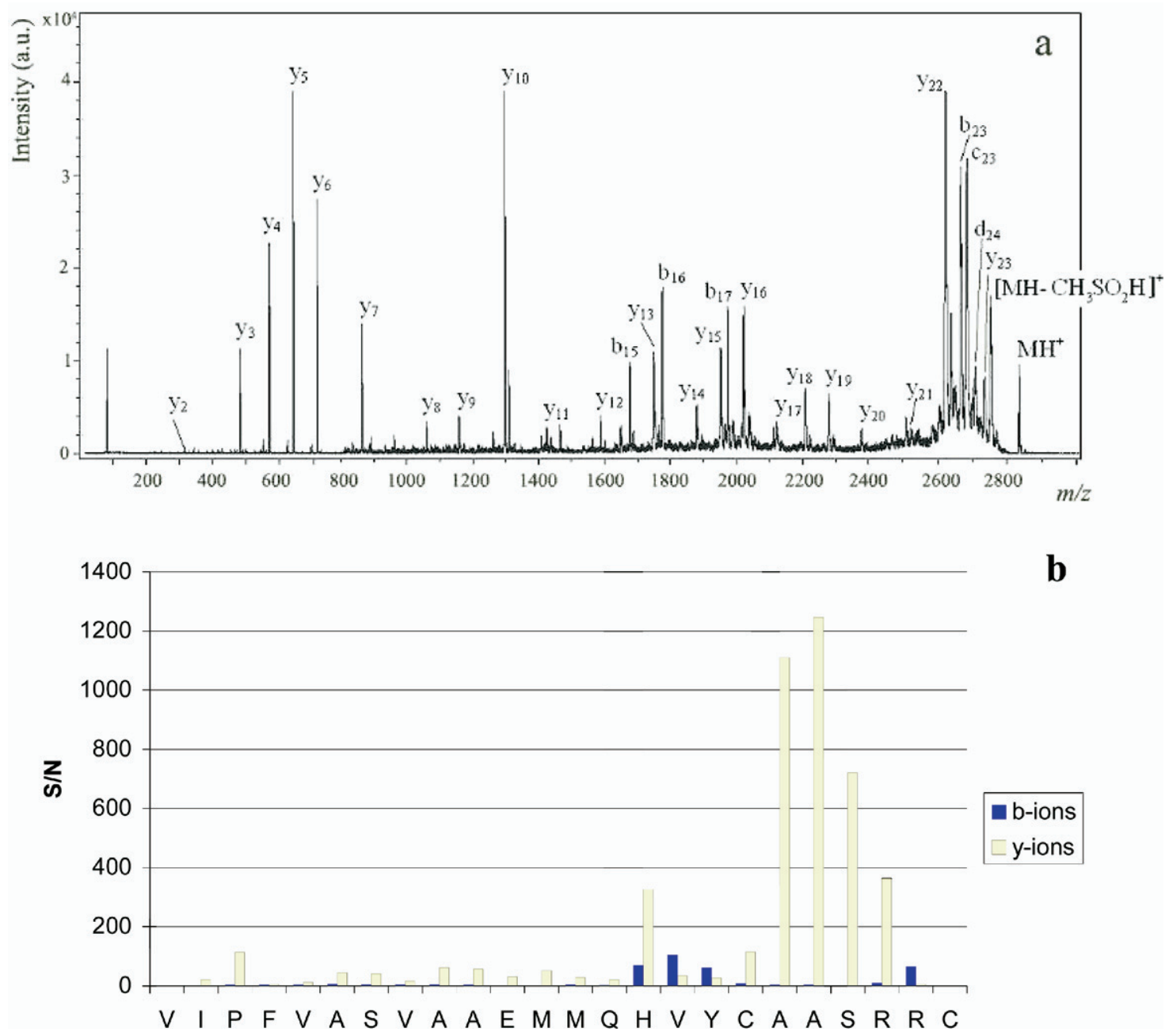

Figure 3. MALDI-TOF/TOF spectrum (a) and $\mathrm{S} / \mathrm{N}$ ratios of $\mathrm{y}$ - and b-ions peaks (b) for oxidized brevinin-1Ra.

Brevinin-1E contains one arginine and three lysines. In conditions of shortage of mobile protons after carboxamidomethylation of this peptide (MALDI experiment) one could hardly expect extensive fragmentation leading to considerable sequence coverage. Figure $5 b$ reflects its selective fragmentation with the formation of the dominant $b_{23}$ and $y_{11}$ ions. The first ion contains all three basic amino acids. The second one appears due to the preferable cleavage at the proline N-terminus [31]. Two additional protons introduced after the S-S bond oxidation process do not notably change the character of the fragmentation as even three mobile protons cannot saturate four basic sites of brevinin-1E. However, lysines in contrast to arginines cannot completely bind protons. Thus the mass spectrum of the oxidized peptide demonstrates a slight increase of signals of all the characteristic ions (Figure 5a). The intensity of peaks of ions $b_{23}$ and $y_{11}$ is increased several times. Similar to the above mentioned peptides, the sum of $\mathrm{S} / \mathrm{N}$ ratios related to the $\mathrm{b}$ - and $\mathrm{y}$-ions that occurred from the cleavages inside the former $\mathrm{C}$-terminal cystine ring is higher for the oxidized sample.

\section{Advanced Fragmentation Processes}

A dramatic increase of the intensities of $b$ - and $y$-ions peaks in MALDI-TOF/TOF study of degradation products from tryptic digest of Ox-BSA and Ox-PBT2 (NVQCRPTQVQLRPVQVR) has been observed earlier $[16,17]$. However, the formation of secondary fragment ions in the MS/MS experiments has not been reported so far.

This study demonstrates that these secondary processes are quite possible. Peaks of secondary fragment ions were observed in the MALDI mass spectra of all the studied peptides with the exception of brevinin-2Ec. Even in the latter case, although the corresponding peaks were recorded, their intensities were extremely low. The appearance of these secondary fragment ions requires the presence of amino acids inducing selective cleavages of the peptide chain. The intact peptides as well as both their derivatives (oxidized and carboxamidomethylated) demonstrated secondary fragment ions peaks due to the cleavages of the peptide bonds in the primary $\mathrm{y}$ - or $\mathrm{b}$-ions, characterized by the most inten- 

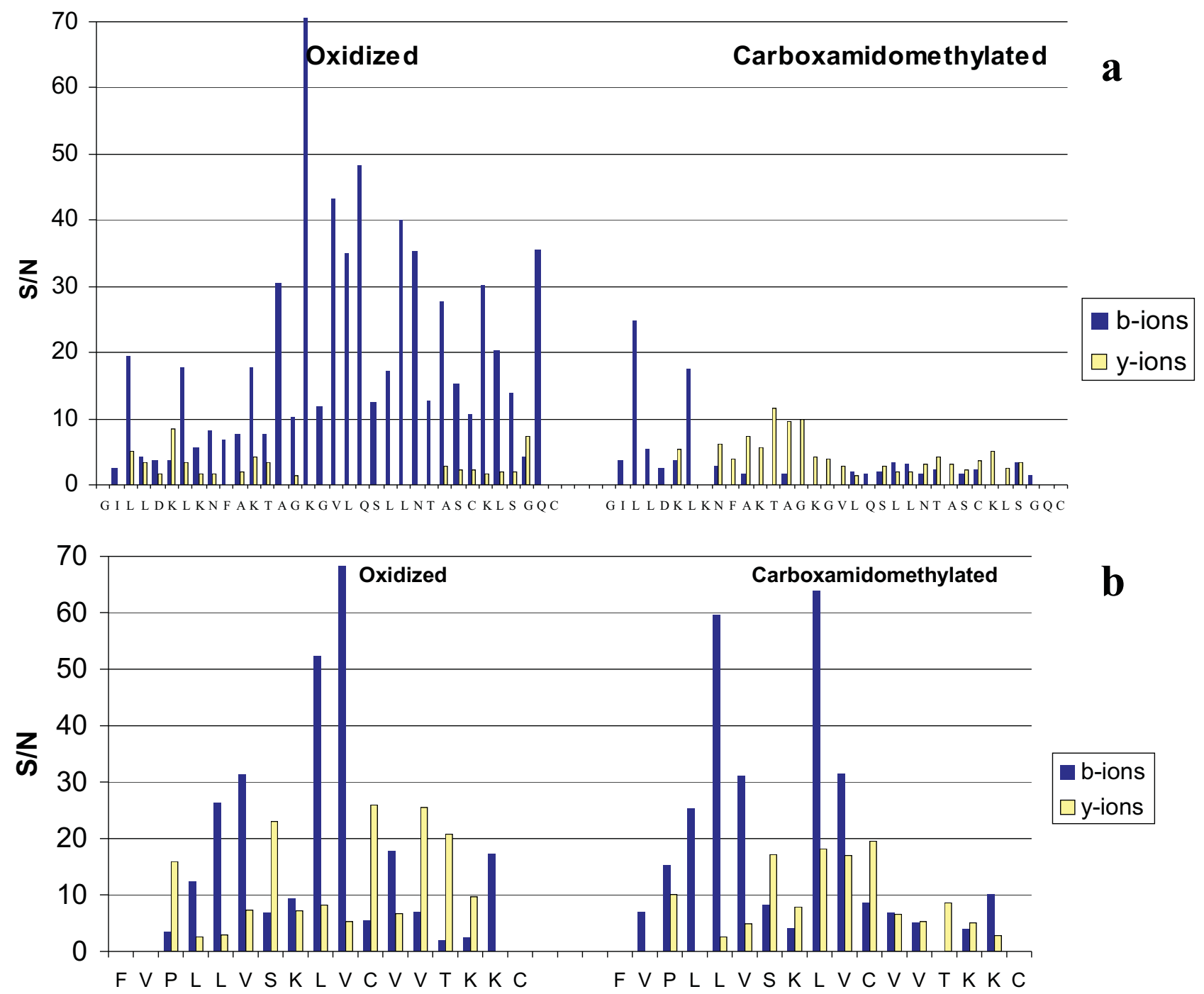

Figure 4. Signal-to-noise ratios for fragment ion peaks. Brevinin-2Ec (a) and brevinin-1AVb (b).

sive peaks. There are three possible mechanisms of their formation. The first one deals with the fragmentation of the primary stable ion with an excess of energy. Thus we observe secondary $b^{\prime}$-ions from the primary $y$-ion or secondary $\mathrm{y}^{\prime}$-ions from the primary b-ion. The second mechanism involves fragmentation of unstable primary b- and y-ions with the cleavages at the most favorable sites contributing to stable secondary ions. Again we observe secondary $b^{\prime}$-ions from the primary $y$-ion or secondary $y^{\prime}$-ions from the primary $b$-ion. Concerted decomposition of the initial molecular ions into three pieces, i.e., with simultaneous elimination of two neutrals from both $\mathrm{C}$ - and N-terminus, should be also taken into account.

At any rate, mass spectra of four mentioned peptides (intact and derivatized) contain peaks attributable to the ions of formally $b^{\prime}$-series resulting from $y$-ion, formed due to the cleavage at the proline N-terminus. The ratio of total ion current of ions of $b^{\prime}$-series to ions of b-series decreases from authentic to oxidized species for all four peptides (Table 1).
Peptides containing lysines (brevinins-1AVa, 1E, and $1 \mathrm{AVb}$ ) or arginines (brevinin-1Ra, 1E) at the C-terminus fragment after the modification of the S-S bond with formation of a b-ion, containing all the basic amino acids. Usually it is the most abundant ion in the b-series. It is possible to formally assume that this ion starts a $\mathrm{y}^{\prime}$-series. Thus, in case of brevinin-1E with the structure FLPLLAGLAANFLPKIFCKITRKC-OH the following peaks of the secondary ions related to the primary $b_{23}$ ion were observed: $[\mathrm{KR}] \mathrm{H}^{+},[\mathrm{KRT}] \mathrm{H}^{+},[\mathrm{KRTI}] \mathrm{H}^{+}$, $\left[\mathrm{KRTIK} \mathrm{H}^{+}\right.$. The ratio of $\mathrm{y}^{\prime}$-ions to the primary b-ions increases in the order brevinin- $1 \mathrm{AVb}<$ brevinin-1AVa $<$ brevinin-1Ra $<$ brevinin-1E. Usually oxidation of S-S bond decreases the favorability of this process in comparison with carboxamidomethylation.

The preferable cleavage in the case of brevinin-1Ra involves histidine position [32] and results in formation of abundant complementary b- and y-ions. Secondary fragment ions of both primary ions are recorded in the mass spectra of this peptide before and after its derivatization. 


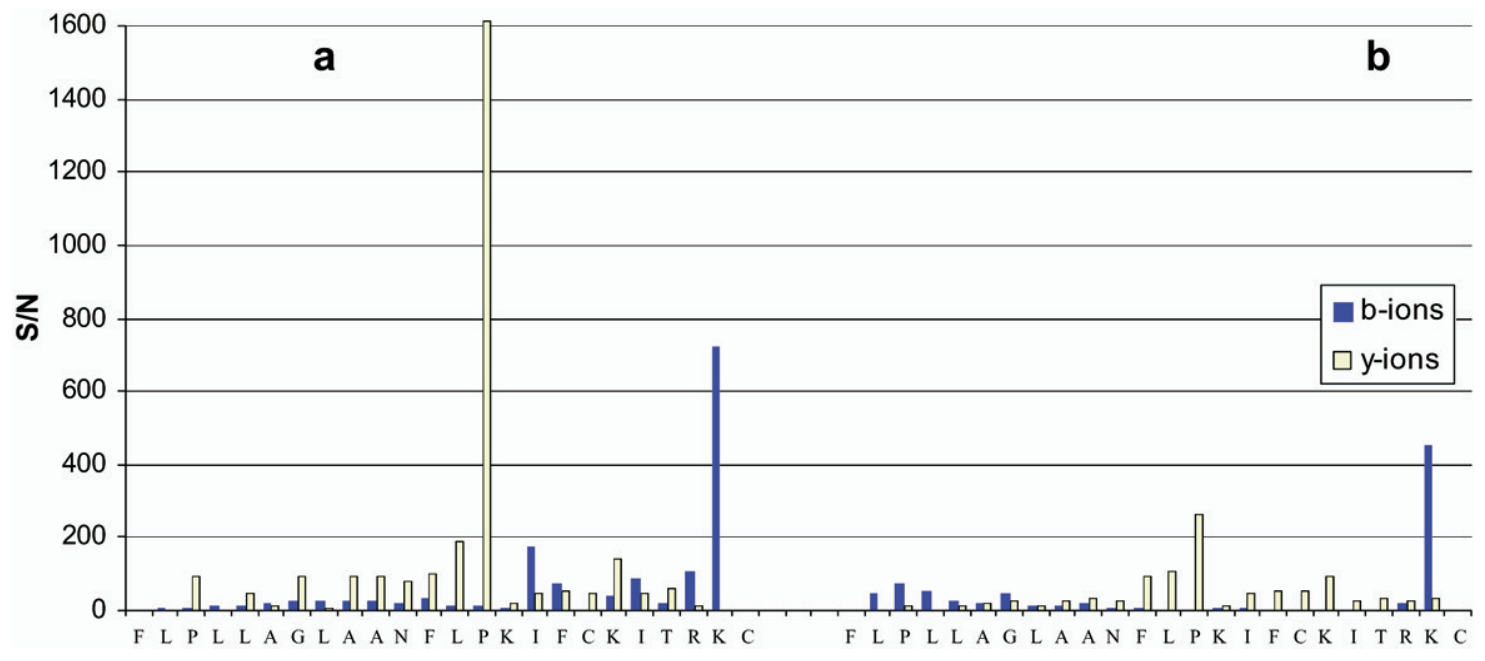

Figure 5. Signal-to-noise ratios for fragment ion peaks of brevinin-1E: oxidized (a), carboxamidomethylated (b).

Brevinin-2Ec (Table 1) does not contain proline, histidine, arginine, or other basic amino acids at the C-terminus. Nonselective fragmentation in this case (both intact and derivatized species) does not contribute to any dominant fragment ions. As a result, there are no notable peaks of secondary ions.

\section{Conclusions}

The aim of both modifications of the S-S bond in natural peptides involved the elucidation of the amino acid sequence inside C-terminal cycle by means of MALDI. The results clearly demonstrated that oxidation of the disulfide bond led to notably higher abundances of b- and y-ions, corresponding to the C-terminal peptide bonds, than reduction/carboxamidomethylation. This conclusion is true for all five peptides studied. Furthermore, the oxidation procedure is simpler than carboxamidomethylation, as it is a one-step process with no purification required. The oxidation is more reproducible. The results were similar each time the peptide was subjected to the process. It was successfully applied to all five peptides, while reduction/carboxamidomethylation failed in the case of brevinin-1Ra, despite all variations of reaction conditions.

The best results for the C-terminus sequencing are achievable if arginine is absent in the peptide structure. In this case two additional protons of sulfonic acid moieties enhance nonselective fragmentation of the peptide bonds along the backbone, resulting in the high sequence coverage in the MALDI-TOF/TOF experiments. Several amino acids (Met, Tyr, Trp) may be modified under performic oxidation conditions. This fact does not complicate the sequencing due to the unique mass of each particular modification. Preliminary mass spectrometric analysis of the intact peptide also simplifies the sequencing, as a result of the probability of mass changes of abovementioned residues.

All the abovementioned makes $\mathrm{S}-\mathrm{S}$ bond oxidation preferable for MALDI-TOF/TOF de novo sequencing of the peptides having C-terminal disulfide cycle, although reduction/carboxamidomethylation may also provide valuable complementary information.

\section{References}

1. Simmaco, M.; Barra, D. Antimicrobial Peptides from Amphibian Skin: What Do They Tell Us? Biopolymers Peptide Sci. 1998, 47, 435-450.

2. Boman, H. G. Antibacterial Peptides: Key Components Needed in Immunity. Cell 1991, 65, 205-208.

3. Hancock, R. E. W.; Lehrer, R. Cationic Peptides: A New Source of Antibiotics. Trends Biotechnol. 1998, 16, 82-88.

4. Hancock, R. E. W.; Diamond, G. The Role of Cationic Antimicrobial Peptides in Innate Host Defenses. Trends Microbiol. 2000, 8, 402-410.

5. Pukala, T. L.; Bowie, J. H.; Maselli, V. M.; Musgrave, I. G.; Tyler, M. J. Host-Defense Peptides from the Glandular Secretions of Amphibians: Structure and Activity. Nat. Prod. Rep. 2006, 23, 368-393.

6. Park, J. M.; Jung J.-E.; Lee, B. J. Antimicrobial Peptides from the Skin of a Korean Frog, Rana rugosa. Biochem. Biophys. Res. Commun. 1994, 205, 948-954.

7. Bilusich, D.; Maselli, V. M.; Brinkworth, C. S.; Samguina, T. Yu.; Lebedev A. T.; Bowie J. H. Direct Identification of Intramolecular Disulfide Links in Peptides Using Negative Ion Electrospray Mass Spectra of Underivatized Peptides. A Joint Experimental and Theoretical Study. Rapid Commun. Mass Specrtom. 2005, 19, 3063-3074.

8. Lilla, S.; Pereira, R.; Hyslop, S.; Donato, J. L.; Le Bonniec, B. F.; de Nucci, D. Purification and Initial Characterization of a Novel Protein with Factor Xa Activity from Lonomia oblique caterpillar spicules. J. Mass Spectrom. 2005, 40, 405-412.

9. Batista, C. V. F.; Scaloni, A.; Rigden, D. J.; Silva, L. R.; Romero, A. R.; Dukor, R.; Sebben, A.; Talamo, F.; Bloch, C. A Novel Heterodimeric Antimicrobial Peptide from the Tree Frog Phyllomedusa distincta. FEBS Lett. 2001, 494, 85-89.

10. Vanhooren, A.; de Vriendt, K.; Devreese, B.; Chedad, A.; Sterling, A.; Van Dael, H.; Van Beeumen, J.; Hanssens, I. Selectivity of Tryptophan Residues in Mediating Photolysis of Disulfide Bridges in Goat $x$ Lactalbumin. Biochemistry 2006, 45, 2085-2093.

11. Burlet, O.; Yang, C.-Y.; Gaskell, S. J. Influence of Cysteine to Cysteic Acid Oxidation on the Collision-Activated Decomposition of Protonated Peptides: Evidence for Intraionic Interactions. J. Am. Soc. Mass Spectrom. 1992, 3, 337-344.

12. Artemenko, K. A.; Samguina, T. Yu.; Lebedev, A. T.; Doyle, J. R.; Liewellyn, L. E.; Belusich, D.; Bowie, J. H. Host-Defense Peptides from the Skin Secretion of the European Marsh frog Rana ridibunda. Massspektrometrija 2007, 4, 79-88.

13. Samgina, T. Yu.; Artemenko, K. A.; Gorshkov, V. A.; Lebedev, A. T. Nielsen, M. L.; Savitski, M. M.; Zubarev, R. A. ESI MS/MS Sequencing of Novel Skin Peptides from Ranid Frogs Containing Disulfide Bridges. J. Eur. Mass Spectrom. 2007, 13, 155-163

14. Sanger, F. The Free Amino Groups of Insulin. J. Biochem. 1945, 39, 507-515.

15. Hirs, C. H. W. Performic Acid Oxidation. Methods Enzymol. 1967, 11 197-199.

16. Dai, J.; Wang, J.; Zhang, Y.; Lu, Z.; Yang, B.; Li, X.; Cai, Y.; Qian, X. Enrichment and Identification of Cysteine-Containing Peptides from Tryptic Digests of Performic Oxidized Proteins by Strong Cation 
Exchange LC and MALDI-TOF/TOF MS. Anal. Chem. 2005, 77, 7594-7604.

17. Dai, J.; Zhang, Y.; Wang, J.; Li, X.; Lu, Z.; Cai, Y.; Qian, X. Identification of Degradation Products Formed During Performic Oxidation of Peptides and Proteins by High-Performance Liquid Chromatography with Matrix-Assisted Laser Desorption/Ionization and Tandem Mass Spectrometry. Rapid Commun. Mass Spectrom. 2005, 19, 1130-1138.

18. Keough, T.; Youngquist, R. S.; Lasey, M. P. Sulfonic Acid Derivatives for Peptide Sequencing by MALDI MS. Anal. Chem. 2003, 75, 157-165.

19. Tyler, M. J.; Stone, D. J.; Bowie, J. H. A Novel Method for the Release and Collection of Dermal, Glandular Secretions from the Skin of Frogs. J. Pharm. Toxicol. Methods 1992, 28, 199-200.

20. Allen, G. Biochemistry and Molecular Biology, Sequencing of Proteins and Peptides. In Laboratory Techniques in Biochemistry and Molecular Biology; Work, T. S.; Burdon, R. H., Eds.; Elsevier: Amsterdam, 1981; p 17.

21. Marshak, D. R.; Kadonaga, J. T.; Burgesss, R. R.; Knuth, M. W.; Brennan, W. A., Jr.; Lin, S. H. Strategies for Protein Purification and Characterization: A Laboratory Course Manual.; Cold Spring Harbor Laboratory Press: Cold Spring Harbor, NY, 1996; p 396.

22. Hunkapiller, M. W.; Hewick, R. M.; Drewer, W. J.; Hood, L. E. High-Sensitivity Sequencing with a Gas-Phase Sequenator. Methods Enzymol. 1983, 91, 399-413.

23. Gorshkov, V. A. Mass Spectrometry Sequencing of the Skin Peptides from Rana arvalis. Proceedings of the International Youth Scientific Forum, Lomonosov-2007, Moscow, April, 2007; p 124.
24. Serjeant, E. P.; Dempsey, B. Ionization Constants of Organic Acids in Aqueous Solution; Pergamon: Oxford, 1979.

25. Bleiholder, C.; Suhai, S.; Paizs, B. Revising the Proton Affinity Scale of the Naturally Occurring $\alpha$-Amino Acids. J. Mass Spectrom. 2006, 17, 1275-1281.

26. Dongre, A. R.; Jones, J. L.; Somogyi, A.; Wysocki, V. H. Influence of Peptide Composition, Gas-Phase Basicity, and Chemical Modification on Fragmentation Efficiency: Evidence for the Mobile Proton Model. J. Am. Chem. Soc. 1996, 118, 8365-8374.

27. Wysocki, V. H.; Tsaprailis, G.; Smith, L. L.; Breci, L. A. Mobile and Localized Protons: A Framework for Understanding Peptide Dissociation. J. Mass Spectrom. 2000, 35, 1399-1406.

28. Tsaprailis, J.; Nair, H.; Somognyi, A.; Wysocki, V. H.; Zhong, W.; Futrell, J. H.; Summerfield, S. G.; Gascell, S. J. Influence of Secondary Structure in the Fragmentation of Protonated Peptides. J. Am. Chem. Soc. 1999, 121 5142-5154.

29. Lagerwerf, F. M.; van de Weert, M.; Heerma, W.; Haverkamp, J. Identification of Oxidized Methionine in Peptides. Rapid Commun. Mass Spectrom. 1996, 10, 1905-1910.

30. Wysocki, V. H.; Resing, K. A.; Zhang, O.; Chen, G. Mass Spectrometry of Peptides and Proteins. Methods 2005, 35, 211-222.

31. Kinter, M.: Sherman, N. E. Protein Sequencing and Identification Using Tandem Mass Spectrometry; John Wiley and Sons, Inc: NY, 2000; p 100.

32. Tsaprailis, G.; Nair, H.; Zhong, W.; Kuppannan, K.; Futrell, J. H.; Wysocki, V. H. A Mechanistic Investigation of the Enhanced Cleavage at Histidine in the Gas-Phase Dissociation of Protonated Peptides. Anal. Chem. 2004, 76, 2083-2094. 